\title{
Thoughts on the Construction of School Productive Training Base in the Higher Vocational Colleges
}

\author{
Zhang Yuchen \\ Henan Mechanical and Electrical Vocational College, Xinzheng, Henan, China
}

\begin{abstract}
The construction of school productive training base in the higher vocational colleges is the inevitable choice to deepen the cooperation between Higher Vocational Colleges and enterprises, and the students could complete work process to produce the product or commodity in a real production environment that is the biggest feature, by this way can realize the unity of teaching, learning and do. At present, the campus productive training base of vocational college has some problems of insufficient quantity, improper functioning, ineffective development and low practice teaching organization. So we must take actions that suit local circumstances to raise the overall level of practical teaching in higher vocational colleges by increasing the lead corporate efforts to build a base, strengthen management, co-ordination base functions and enhance the soft power, we can realize from "lead enterprises into the school" to" end teaching into the enterprise".
\end{abstract}

Keywords - schools productive training base, lead enterprises into the school, send teach into the enterprise

\section{高职院校建设校内生产性实训基地的思考}

\author{
张玉臣 \\ 河南机电职业学院, 新郑, 河南, 中国
}

摘 要 校内生产性实训基地建设是高职院校校企合作深化的必然选择, 其最大的特点是学生在校内真实的生产环境中实训完整 的工作过程, 生产出产品甚至商品, 实现教学做的统一。目前, 高职院校的校内生产性实训基地存在数量不足, 功能发挥不当、开发 不力, 实践教学组织水平较低等问题, 我们必须 “因企制宜”, 加大引企共建基地的力度, 强化管理, 统筹基地功能的发挥, 增强软实 力, 实现由 “引企入校” 向 “送教入企” 的升华, 全面提升高职院校的实践教学水平。

关键词＼cjkstart校内生产性实训基地，引企入校，送教入企

\section{1. 引言}

高职院校要改善实训、实习的条件。就必须联系行业 企业, 建设校内生产性实训基地。高职院校校内实训基地 的生产化, 是专业实验方法和技能的进一步深化与应用, 是学生校外顶岗实习以及将来就业的重要基础, 也是高职 院校深化改革。彰显办学特色, 提升办学水平, 提高人才 培养质量的重要环节。在 2006 年 11 月 13 日召开的国家示 范性高等职业院校建设计划视频会议上, 时任教育部部长 周济明确指出了 “高职院校与企业和市场更紧密地结合起 来” 的校内生产性实训基地建设的方向和路径。因此 “高 等职业院校要按照教育规律和市场规则, 积极探索校内生 产性实训基地建设的校企组合新模式。”

\section{2. 校内生产性实训基地及其特点}

校内生产性实训基地是指高职院校在校内通过新建或 改造原有实验实训室、引企入校、创办专业公司和组建研 究所等方式, 依据工厂化、车间式进行布局和设备选型, 参照企业员工管理、成本控制、质量监控、绩效考核、薪 酬激励等管理模式建立起来, 具有生产功能的学生实践教 学场所。因此。实践教学功能和生产功能是校内生产性实 训基地的两大基本功能, 学生通过产品生产的真实过程。 实现提升职业技能、培养职业道德的实践教学目标。

校内生产性实训基地最大的特点是学生在校内就可以 感受真实的生产环境、真实的生产任务、真实的企业管理 和市场化的评价标准, 从而能够满足实际操作技能培训和 职业素养熏陶的基本要求。体现理论与实践、教与做的高 
度统一。

校内实训基地生产或技术服务的设备与企业大同小 异, 其区别仅仅是规格和型号的不同。就是设备的布局、 文化氛围营造也参照企业: 校内实训基地的生产任务可以 来源于社会真实的项目 (即生产商品), 也可以是模拟的教学 任务(即生产产品)。但对产品的用途、性能、设计、选材、 成本、工艺选择、验收标准、完成时间等都按照企业生产 的要求。对技术服务的对象、内容、标准、技术规范、最 终成果的形式等也严格按照市场的要求: 校内实训基地管 理模式包括考勤、调度、计划、制品、定置、统计、“ $6 \mathrm{~S}$ ” 及安全与文明生产管理至着装等都严格参照企业的制度执 行, 以实现实训过程与生产过程的一致; 校内实训基地生 产的产品或技术服务成果的质量、效率、成本、工艺选择 等在接受学校 “教学标准” 评价的同时, 还要参照企业、 客户对产品的验收标准进行综合评判。总之, 校内生产性 实训基地生产情境和工作氛围的车间化, 生产任务的真实 化。运行和管理模式的企业化, 成果评价市场化。是校内 生产性实训基地的基本特点。

校内组织生产性实训与企业的实际生产最大的区别在 于目标不同: 校内生产性实训。以培养人为主要目标, 而 企业生产的主要目标是赢利, 正是目标上的区别, 决定了 校内生产性实训在实训过程中, 学生不是生产的 “机器”, 而是 “职业人” 的培养。在实训过程中产品的选择需具有 典型性、递进性。参加实训的学生和学生实训的岗位具有 轮换性。

校内生产性实训基地的理想状态是通过引进企业的资 金、设备、技术、管理和文化, 对外承接 “订单” - - 生 产任务或技术服务, 在专业教师和企业师傅的指导、监控 下, 以学生为主体, 通过分工协作和有序轮岗, 完成 “订 单” 的任务。其质量接受客户检验, 其生产和管理成本(包 含支付顶岗实习学生一定的薪酬)独立核算, 在提升学生技 能、职业素养和完成教学任务的同时, 有一定的利润, 实现 基地 建设的可持续发展。

\section{3. 目前校内生产性实训基地建设存在的主要问题}

\section{1 基地数量不足}

我国高职教育起步较晚, 但发展很快。实训条件滞后 成为制约高职人才质量提升的突出问题。受学校办学资金 制约, 能改造或新建校内生产性实训基地的数量有限; 引 进产品生产型企业虽然能够提供较多实习岗位, 但能够引 进的企业毕竟少; 引进技术服务型企业虽然相对容易, 但 往往规模采大服务项目数和业务量较小, 能够组织学生参 与生产性实训的时间和人数还是有限, 校内生产性实训占
实践教学的比例偏低。究其原因, 一是政府和相关部门缺 乏法律制度和具体方案的指引; 二是校企工学结合还缺乏 更广阔的思路和能够提供借鉴的经验。学校的主观能动性 发挥还不够; 三是企业缺乏人才战略的长远规划和承担提 升人口素质的社会责任; 因此, 校企共建校内生产性实训 基地, 往往是学校热情很高, 企业却比较冷淡。

\section{2 基地功能发挥不当、开发不力}

由于校内基地的生产与实训之间虽具有同一性(通过 生产可以提升学生的技能, 提升技能后的学生反过来促进 生产, 提高生产的质量和效益), 但两者又有对立性(生产目 标与实训目标的不同决定了实施原则和方法的差异, 生产 会妨碍实训。实训也会影响生产)。校内生产性实训基地重 生产、轻实训的现象常常发生, 企业经常以生产工艺复杂、 工期紧、安全责任重大等理由减少学生参与生产实训的人 数和时间, 弱化了校内基地最重要的实践教学功能; 对基 地的技能考证、社会培训、技术研发和成果展示等其他功 能开发不力, 导致基地经济和社会效益不明显, 不能扩大 校企合作共赢的结合点, 无法满足可持续发展的需要。究 其原因, 一是学校对基地建设的定位不准、目标不清、主 动服务社会的意识不强; 二是学校缺乏统筹生产性与实训 性、经济效益与人才培养之间互利共赢的能力, 缺乏整合 资源开发基地其他功能的能力; 三是专业教师缺乏依据市 场变化及时开发实训项目、依据企业生产规律组织实践教 学的能力。

\section{3 基地实践教学的组织水平较低}

实训内容缺乏典型性、递进性和系统性。引进的企业 生产什么产品, 学生就实训什么内容。东一榔头西一棒子, 实训项目安排随意、没有规划: 缺少系统考虑, 与专业建 设、课程建设、教学团队建设对接程度低, 实训的生产过 程和产品缺乏典型性和递进性, 校内生产性实训基地与校 外基地缺乏互补性。以为把企业引进学校以后, 只要组织 学生实训。生产出产品, 就达到了引企业入校的目的。

实训目标模糊、实训方法机械。以单一的生产环节取 代完整的工作过程, 只重视生产环节的操作规范、安全管 理、时间和耗材的控制, 忽视实际生产前的任务分析、设 备和原材料备选方案的论证, 工艺方法和人员组织的优化、 员工素养的要求、标准的制定, 也不重视生产后的产品验 收、评价与反思以及对产品没计及工艺的改进等。过于顾 虑安全风险和时间成本, 实践教学方法以灌输为主。学生 自主学习、探究学习和创新学习激发不够。

实训指导师数量不足、指导水平低。学校的老师往往 实践技能比较弱, 企业师傅只知道怎么做, 但缺少教的经 
验; 既懂做、又懂教的双师型教师数量严重不足。

这种重硬件轻软件、实践教学组织水平低的状况, 根 源在于学校没有实现从 “引企入校” 到 “送教入企” 的提 升。

\section{4. 目前校内生产性实训基地建设存在的主要问题}

\section{1 “因企制宜”，加大引企共建=建基地的力度}

（1）引进技术服务型企业共建基地易操作, 做大做强 是目标。

技术服务型企业主要是利用自身的智力资源和先进的 仪器没备、技术, 通过咨询、培训、评价诊断、分析检测、 鉴定、设计、技术开发、加工、代理、修理修配等形式, 为社会提供服务, 其产品是智力劳动成果为主, 表现形式 往往是检测报告、鉴定意见书、发展规划、背销方案、设 计图纸、居间合同等。

由于人力资本是技术服务型企业的 “第一资源”, 对于 企业来说, 共建校内生产性实训基地既可以共享学校的场 地、师资和设备, 减少基本建设和配套。设施的投入, 又 节约人头费用的支出和管理成本; 在组织学生进行技术服 务的过程中, 消耗性材料的成本易控制, 服务质量易把关 (既有老师和师傅的指导, 也有同组同学的相互监督, 更有 质量抽监制度的保障, 出现质量问题, 完全能够及时采取 低成本的补救措施); 同时, 与学校合作可以增加企业公信 度, 增强对客户的吸引力; 企业还可以借助学校的师资、 科研、设备等优势, 拓展经营范围, 开拓新业务。因此, 技术服务型企业乐意进驻学校: 共建校内生产性实训基地。

对于学校来说, 许多技术服务型企业无污染无噪音, 对日常教学管理几乎没有负而影响; 技术服务型企业都是 先接单, 约定收费数额和方式后再提供服务, 共建校内生 产性实训基地无亏损之风险; 学校还可以利用企业的资金、 设备、资质、技术指导力量以及相对稳定的 “订单”, 在真 实的 “社会化” 的环境中提高学生技能, 培养学生严谨规 范的工作态度和团队协作的意识。因此, 学校很欢迎技术 服务型企业进驻学校, 共建校内生产性实训基地。

由于引入技术服务型企业共建基地, 校企互利共赢的 结合点多, 所以做大做强是目标。做大就是加大引进力度, 扩大共建数量。建筑没汁、装潢艺术设计公司、产品质量 检测站、会计师事务所、律师事务所、安全生产评价中心、 网络服务机构、产品研发中心、技术培训中心、汽车维修 公司等都可以与相关专业共建校内生产性实训基地。做强 就是要在质量上不断提升合作企业的技术含量, 引进符合 政府导向、有广阔市场前景和更高技术含量的企业; 要根 据地方经济社会发展的状况, 对引进的技术服务型企业进
行动态管理, 及时淘汰、改造和更新; 在条件成熟的时候, 学校可以根据法律、法规的规定, 自主成立的专业老师为 骨十、吸收社会专家参与的学校专业性公司。

(2) 引进产品生产型企业共建基地困难多, 创新渠道、 机制是关键。

引进合适的产品生产型企业入校。共建基地受到的制 约因素多: 第一, 引进企业的生产技术含量要适中。技术 含量高、生产工艺复杂, 学生上手慢。在进行生产性实训 时效率就低, 废品率高。企业将无法承受原材料和生产时 间的高成本; 技术含量过低、生产工艺过简单, 对学生技 能提升意义就不大。如果把学生当作廉价劳动力, 学生会 产生对立情绪。第二, 引进的企业需无污染、低噪音。否 则学校会得不偿失。第三, 引进企进的产品要处于成长或 成熟期, 生产必须有经济和社会效益; 引进的企业设备功 能多, 产品可以升级换代, 这样才能保证合作行较长的时 问。第四, 学校引进的企业或车间生产有相对的独立性, 与上一工序和下一工序可以相对剥离, 考虑到运输成本和 管理成本，投资企业不能离学校太远。

产品生产型企业影响生产成本的因素多, 不易控制; 企业追逐利润与学校人才培养、企业产品单一与学校教学 多样的矛盾不易克服; 与企业共建的产品生产型校内基地 的管理与运行也相对困难, 因此。创新渠道、机制是关键。

学校要积极发掘与企业、政府、行业之间资源共享、 合作共赢的结合点, 主动跑企业, 通过政府搭台、社会搭 台、专业搭台、中介搭台及项目搭台等途径。走访行业协 会, 了解与学生实践有关的产品生产型企业。对支撑当地 经济和社会发展的骨干企业按地域、按专业进行分类, 熟 知企业产品、产量、技术含量、从业人员规模及工种、销 售范围、盈亏等情况, 建立信息档案。对信息库里的企业 进行认真分析, 寻求互利共赢的结合点, 探索与产品生产 型企业共建校内实训基地的新渠道、新机制。要根据教学 的需要, 按照从易到难、循序渐进的原则引进中等技术难 度的、其产品就有典型教学意义的企业入校, 并逐步建立 由简到繁、分层次的系列产品生产型实训基地, 以满足不 同年级的顶岗实习、实训。在积累一定经验后, 对于有条 件的强势专业, 可以自主成立专业生产公司使之成为 “校 内教学工厂”, 对外承接生产业务。

(3) 自主研发, 变企业生产设备为学校的实训设备。 要激发教师投身实训基地建设的积极性, 激励教师自 主研发、制作生产性实训设备。如缩小企业的大型生产设 备, 整合典型的生产工艺等。自主开发适宜实践教学的生 产性实训设备, 既提升教师的研发水平。又加强实践教学 的针对性, 既节约设备的投入经费, 也节约设备的使用和 维护费用。 


\section{2 强化管理, 统筹基地的功能发挥}

（1）建章立制, 保障教学实训主功能。

校内生产性实训基地的最主要功能是教学实训, 为保 障其不偏离主要目标, 合同或章程中除了对资金、设备、 场所、人员、项目管理等作出约定外, 还必须以人才培养 为落脚点, 明确校企双方对人才培养所承担的权利和义务。 明确基地常年提供多少工位、多少时间、多少项目用于学 生实训和顶岗实习。同时, 要建立、健全基地内部的管理 和运行机制、校企双方管理人员的交流沟通机制, 落实机 构和人员, 明确职责, 保证基地教学实训功能的实现。

要建立校内生产性实训基地建设的考核和预警机制。 对一定时间内无法提供一定项目、工种供学生实习、实训 的, 先给予一定期限的整改, 经整改仍然不符合要求的, 终止与企业的合作。通过不断的更新。实现基地建设的不 断优化和提升。

（2）拓展功能, 实现校企合作效益最大化。

校内生产性实训基地是教学效益与社会经济效益的统 一体。学校要整合政府、行业的资源, 根据不同校内生产 性实训基地条件、实力的差异, 分层次、有计划地拓展技 能考证、员工培训、技术研发、成果展示等功能: 同时, 要为引入的企业办理享受税费优惠政策、申报高新技术企 业、申报国家或省部级课题、组织技术攻关提供更多服务, 为企业开拓经营领域提供帮助。只有不断扩展校企互利共 赢的结合点, 才能实现基地效益最大化, 才能实现校内生 产性实训基地的可持续发展。如我院在省政府的支持下， 把校内基地拓展成融中职教师培训、人才培养、技能鉴定 和技术研发为一体的区域共享型实训中心, 就是成功的案 例。

\section{3 深化 “送教入企”, 全面提升基地实践教学组织水平}

“引企入校” 只是高职院校校内生产性实训基地建设 的第一步, 它能够解决基地硬件设施与企业真实生产的“形 象” 问题, 即生产设备、工艺、产品, 以及上墙的生产管 理流程和制度与企业生产环境相似。要实现基地建设与企 业真实生产的 “神似”, 就必须在重视硬件投入的同时, 加 强基地的软件建设。转变基地管理理念, 统筹基地功能发 挥, 在 “引资” 的基础上 “引智”, 实现由 “引企入校” 向 “送教入企” 的深化。引导教师围绕基地的实践教学功能, 在深入思考实训什么内容、用什么方法实训、由谁来指导 实训、为什么要这样组织实训、还有没有更有效的内容方 法来替代等问题的过程中, 熟知地方的产业发展、工艺水 平、产品质量, 领会基地建设的本质要求。把企业的众多 要素渗透到职业教育人才培养的全过程。把产业发展对员
工职业能力、核心技能的要求渗透到专业建设的方方面面, 能够融会贯通甚至游刃有余地在不同时间组织基础不同的 学生实施个性化的生产实训, 即使实训硬件条件并不足, 但实训效果不打折, 达到 “尤招胜有招”, 的境界。

（1）优化实训项目，体现实训内容的典型性、递进性 和完整性。选择的实训项目要具有典型性。要让学生通过 一至二个实训项目的生产, 掌握相应技能后, 具备举一反 三、触类旁通的迁移能力。可以独立完成相同或相近的生 产任务。如传感器课程在篎选实训项目时就需要考虑分析 对象(温度、压力、流量等) 以及基本分析方法的典型性。以 避免简单机械的重复。

实训项目的组合要具有递进性和完整性。递进性就是 在组织若干具有典型意义的实训项目时, 要遵照由易到难、 循序渐进的教学规律, 合理有序的编排。完整性就是每一 个实训项目都是一个完整的工作过程(虽然应该各有侧重, 但都包含从接受生产任务到调研、制订方案、决策、安排 生产、检查反馈、验收评价等要素), 某一专业所有实训项 目的组合形成一个有机的整体，应涵盖该专业对应就业岗 位所有基础技能和关键技能以及基本的发展技能, 如果工 业分析与检测专业完成所有项目的实训后, 还有常用仪器 没有接触、基本方法掌握不全, 实训项目的组合就缺乏完 整性。

实训项目优化组合的依据是专业、课程对学生技能发 展的要求。学校要引进社会智力资源, 发挥专业建设指导 委员会的作用, 根据毕业生的就业岗位, 分析岗位的基本 技能、核心技能和发展技能, 合理安排课程体系, 紧贴地 方经济和社会发展, 对核心课程进行基于工作过程的课程 开发和典型实训项目的系列开发, 不断更新、积累, 实现 优化组合。

（2）优化结构, 建设系统化基地。制订校内生产性实 训基地建设的整体规划。

学校要根据专业、课程、实训内容等要求对实训基地 建设制订出整体的规划, 分阶段、分层次组织实施, 力求 校内校外基地互补，校内基地结构合理。

引进合适的企业共建基地。根据典型实训项目的系列要求, 有针对性地引进企业共建校内生产性实训基地, 按项目、 分层次组织生产性实训, 鼓励技能熟练的学生参与顶岗并 获得劳动报酬。作为学校勤工俭学的方式之一。

实现 “引企入校” 向 “送教入企” 的深化, 准确把握 基地建设的本质。学校按照生产性要求。改造或自建一批 有一定数量、结构相对合理的校内生产性实训基地, 根据 实训要求, 引进企业某一元素(产品、技师、设施、工艺、 管理、文化等)或某几个元素的组合, 结合地方产业发展的 不同状况, 有序、灵活组织系列生产实训, 坚持以服务为 
导向、以就业为宗旨, 最终使学生在掌握常用仪器设备、 基本工艺方法、具备良好职业道德的基础上，懂得在不同 类型企业、不同生产环境、不同设备条件下能够因地制宜 选择合适的装备、使用经济的方法、组织有效的管理, 生 产出客户和老板都满意的产品, 实现基地建设的真正目标。

校内基地建设与校外基地建设统筹兼顾。所有的实训 项目都在校内基地完成既不现实, 也没必要, 学校必须把 校内基地建没与校外基地建设统筹兼顾, 有侧重有分工, 通过校内、校外两个基地的互补, 共担学生教学实训的重 任。

（3）增强软实力, 提升生产性实训基地的管理水平。

加大培训力度, 提升教师和企业师傅的自身素质和指 导水平。工学结合的课程开发、实训项目的不断优化、完 整工作过程的指导评价、对行业发展前景的熟知, 在学生 技能相对熟练之时, 不仅能指出学生操作过程中存在的不 足或问题, 还能给学生指明改进的方向, 这些都对实训指 导教师提出了更高的要求。学校要通过鼓励年轻教师下企 业锻炼、骨干教师利用专长服务社会等方式提升教师个体 的实践技能, 通过教育理论的培训提升兼职教师的个体教 学技能, 通过专兼一体化管理的教学团队建设提升师资整 体实力。

不断积累, 提高统筹基地生产性与实训性、经济效益 与人才培养之间互利共赢的能力。基地管理人员和实训指 导老师要及时掌握引进企业的生产规律, 明了企业的需求, 加强安全教育, 在企业生产的淡季组织学生实训, 在企业 生产的旺季安排技术熟练学生勤工俭学, 实现生产与实训 的相互促进、工学结合的互利共赢。

拓宽思路, 开发软件。对于难以实现实际生产的化工、 安全、制约类专业的校内实训, 要利用现代信息技术开发 软件, 在校内建立虚拟车间、虚拟工艺、仿真软件等, 为 学生实际操作提供仿真操练的机会, 并通过实地考察企业 来解决与实际生产的对接问题。

校内生产性实训基地建设的发展在于创新机制。只要 我们在大局上从社会、企业、学校和学生的根本利益着眼, 在具体工作中寻求合作共赢的结合点, “因企制宜” 引企共
建的同时, 将企业的观念、规范、管理、文化和师资等渗 透到高职人才培养的全过程, 实现 “引企人校” 到 “送教 入企” 升华, 高职院校的实践教学水平必将上一个新的台 阶。

\section{参考文献(References)}

[1] Li Liming. On the vocational college's productive training base construction. Journal of Shandong Youth Administrative Cadres College, 2007(05):117-119

[2] Ma Qiang, Fu Yanru.Study based on an open park productive vocational training. Vocational Education Research, 2010 (08):65-67

[3] Linda Wang,Xiaochuan Liang,Ling Wang. Review of productive training vocational colleges. Value Engineering, 2011(12):45-46

[4] Li Po.Research and Practice of vocational schools productive training base construction mode. Journal of Education and Vocational, 2013(08):78-79

[5] Luyun Fan. Higher education reform and building productive training courses to build linkage between research groups. Vocational and Education, 2011(02):25-27

[6] Liu Haolin. Carrying out in vocational mechanical specialty training on research and production. Chinese Vocational and Technical Education, 2012(04):67-68

[7] LU Rongping. Productive Training Base in Vocational Colleges: connotation, characteristics and construction strategy. Journal of Vocational and Technical Education, 2011(12)43-45

[8] Liu Yang. The construction and management feasibility of vocational college's productive training base. Journal of Chongqing Electric Power College, 2013(08):28-30

[9] Qing Wu. Research on the issue of productive vocational training base. Vocational College Education Forum, 2009(03): 76-78

[10] Cheng Yan.Construction and Discussion of the vocational school productive training base. Journal of Jiamusi Education Institute, 2012(01):56-58 